\section{CAG interactive lecture series: A Web-based learning program}

\author{
Richard N Fedorak MD FRCPC, Chair, CAG Interactive Lecture Series
}

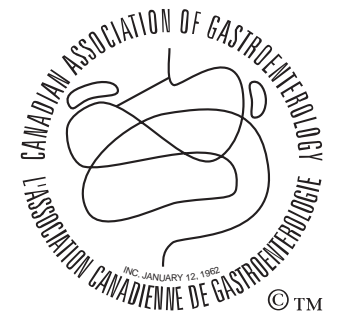

En français voir page 68
$\mathrm{T}$ he Canadian Association of Gastroenterology (CAG) recognizes the importance of its members being able to maintain Royal College of Physicians and Surgeons certification. To this end, certification credits can come from attending a host of CAG-developed and -supported educational programs.

Because an individual's learning cannot always take place at the precise moment that a lecture or symposium is being given, the CAG, in partnership with CD-Pharma Interactive Medical Productions Inc (Canada), has developed the CAG Interactive Lecture Series program. This is a vast database of interactive presentations by key national and international experts, covering the hottest trends, controversies and developments in the diagnosis and management of a variety of gastrointestinal disorders.

\section{DESCRIPTION OF THE PROJECT}

The CAG Interactive Lecture Series is a novel and innovative 'high tech' concept in continuing professional development. It is an updateable CD-ROM that works like a key, giving CAG members access to a wide and unlimited selection of interactive state-of-the-art presentations by experts in gastrointestinal sciences. Past and current presentations may immediately be accessed directly from the CD-ROM, while new online presentations made available throughout the year may be easily downloaded and automatically incor- porated into the program through special online access that only the CD-ROM can permit.

There are currently close to $30 \mathrm{~h}$ of scientific presentations accessible through the CAG Interactive Lecture Series program, and we anticipate adding at least 30 new lectures each year.

CAG members will be able to access this unlimited database of online presentations $24 \mathrm{~h}$ a day, seven days a week, and at a time and venue that is suitable for their learning. In addition, they will be able to claim credits for viewing each of these under either section 2 or section 4 of the Royal College of Physicians and Surgeons of Canada Maintenance of Certification Program.

The CAG Interactive Lecture Series will also provide a direct link to the official Web site of the CAG and will automatically update all members via e-mail whenever a new state-of-the-art presentation or lecture is added online.

The CAG Interactive Lecture Series will officially be launched at the Canadian Digestive Diseases Week in February 2002. Because the CAG Interactive Lecture Series is currently made possible through an unrestricted educational grant from Abbott Laboratories, Ltd (Canada) and Axcan Pharma Inc (Canada), we invite you to contact your local representatives to obtain your own copy of this exceptional educational program. We know that you will find it a truly invaluable tool in your own learning and continuing professional development.

Information and details for the 2002 Canadian Digestive Diseases Week available on the CAG Web site: http://www.cag-acg.org

The CAG is proud to acknowledge its Benefactor Corporate Sponsors:

Abbott Laboratories Ltd. AstraZeneca Canada Inc.

Axcan Pharma Inc. 


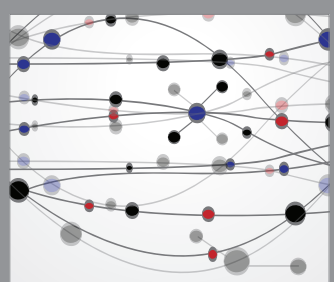

The Scientific World Journal
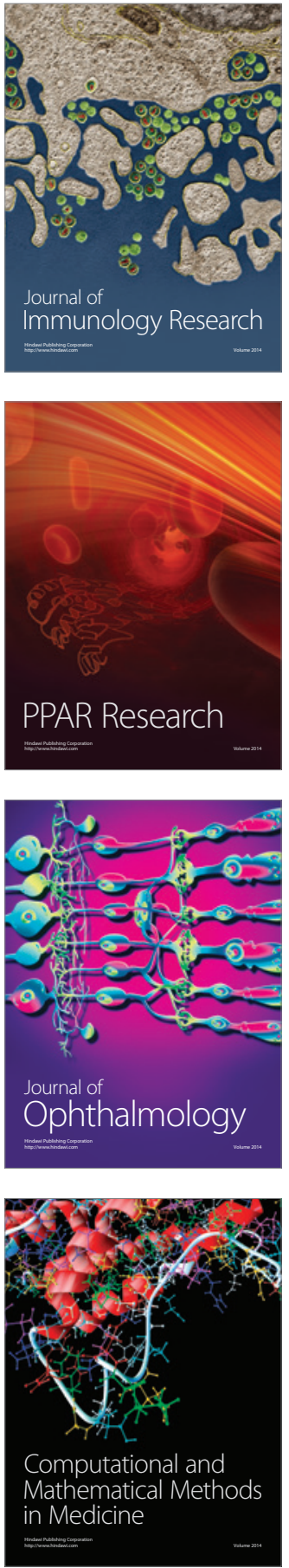

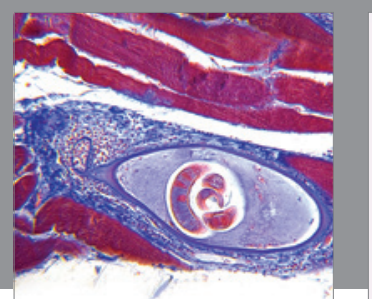

Gastroenterology Research and Practice

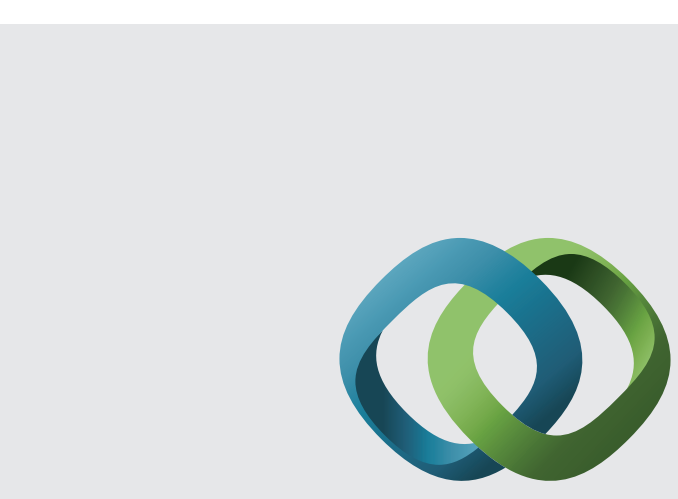

\section{Hindawi}

Submit your manuscripts at

http://www.hindawi.com
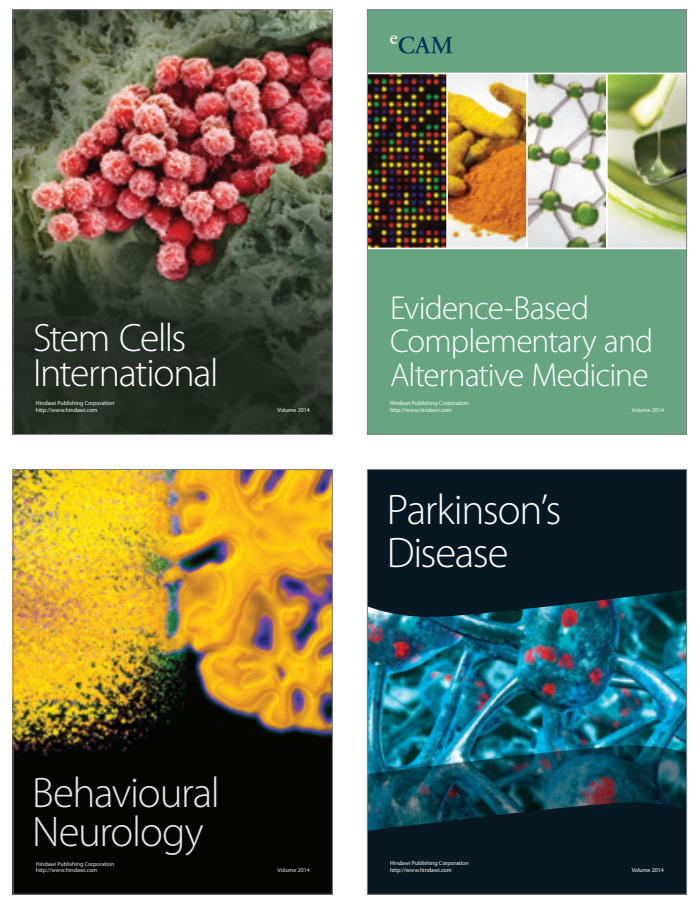
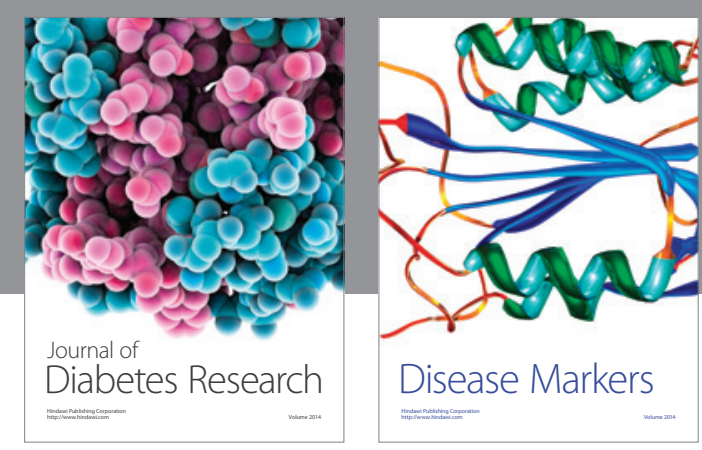

Disease Markers
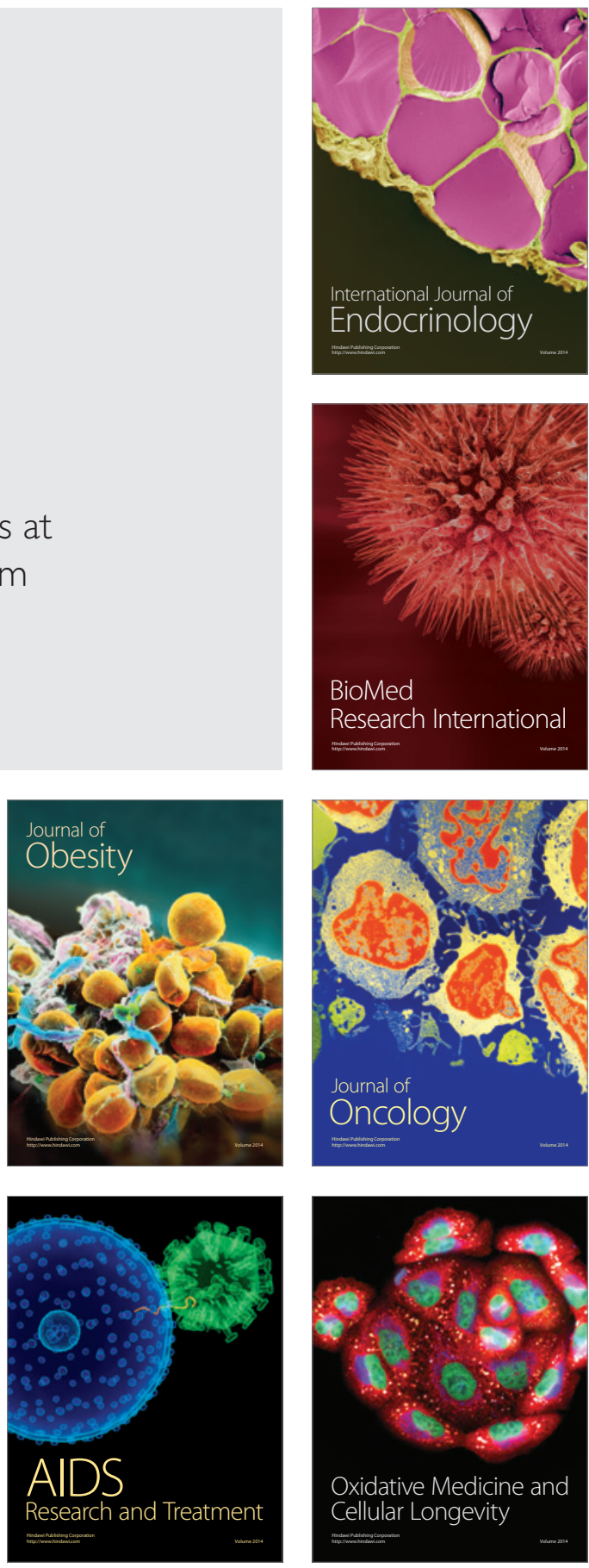